\title{
DIAGNÓSTICO DA SITUAÇÃO ATUAL DA ADOÇÃO DOS SISTEMAS INTEGRADOS DE GESTÃO (ERP) NAS MICRO E PEQUENAS EMPRESAS BRASILEIRAS PESQUISADAS
}

\section{DIAGNOSIS OF THE CURRENT SITUATION OF THE NETWORK OF INTEGRATED MANAGEMENT SYSTEMS (ERP) IN THE MICRO AND SMALL BRAZILIAN ENTERPRISES}

\author{
Recebido: 25/03/2018 - Aprovado: 14/03/2018 - Publicado: 26/06/2018 \\ Processo de Avaliação: Double Blind Review
}

\author{
Fabio Rios Stump $\mathbf{f}^{1}$ \\ Mestre em Gestão e Estratégia pela UFRRJ. \\ UFRRJ - Universidade Federal Rural do Estado do Rio de Janeiro \\ fabiostumpf@tecsoftware.com.br
}

\section{André Yves Cribb}

Pós-Doutor e Pesquisador.

Embrapa Agroindústria de Alimentos

andre.cribb@embrapa.br

RESUMO: Focando nas micro e pequenas empresas brasileiras, do ponto de vista do receptor da tecnologia, na adoção de sistemas integrados de gestão, ou como internacionalmente conhecidos os Enterprise Resource Planning (ERP), o presente estudo buscou diagnosticar a situação atual da adoção dos sistemas integrados de gestão (ERP) nas micro e pequenas empresas. Foram caracterizadas as micro e pequenas empresas de acordo com o seu faturamento no ano de 2015. Buscou-se entender o processo de adoção de tecnologia como uma visão mais abrangente da implantação desses sistemas. Foi coletada uma amostra estratificada de 411 empresas, realizada no segundo semestre de 2016, com a presença de empresas entrevistadas em todos os 27 estados brasileiros. Os resultados obtidos possibilitaram diagnosticar a situação

\footnotetext{
${ }^{1}$ Autor para correspondência: UFRRJ - Universidade Federal Rural do Estado do Rio de Janeiro - Rodovia BR 465, Km 07 , s/n -, 23890-000 Zona Rural, Seropédica - RJ, Brasil.
} 
atual da adoção dos sistemas integrados de gestão (ERP) nas micro e pequenas empresas brasileiras pesquisadas. Levou-se em consideração o ponto de vista do receptor da tecnologia.

Palavras-chave: Adoção de Tecnologia, Inovação, Micro e Pequenas Empresas, MPE, ERP.

ABSTRACT: By focusing on the micro-and small Brazilian companies, from the point of view of the technology recipient, on the adoption of integrated management systems, or as internationally known Enterprise Resource Planning (ERP), this study sought to diagnose the current situation of the adoption of integrated systems (ERP) in micro and small enterprises. It was characterized micro and small companies according to their billing in the year 2015. It was sought to understand the process of adopting technology as a more comprehensive view of the implementation of these systems. A stratified sample of 411 companies was collected in the second half of 2016, with the presence of companies interviewed in all 27 Brazilian states. The results obtained allowed to diagnose the current situation of the adoption of integrated management systems (ERP) in the micro and small Brazilian companies surveyed. The technology receiver's point of view was observed.

Keywords: Technology Adoption, Innovation, Micro and Small Enterprises, MPE, ERP.

\section{INTRODUÇÃO}

As micro e pequenas empresas brasileiras sofrem fortes pressões competitivas. Por isso, a utilização de tecnologias tem-se tornado necessária e até mesmo crucial para que as mesmas sobrevivam no mercado e consigam prosperar. No entanto, esse processo de crescimento e de mudança tecnológica são muitas vezes vistos como uma proposta assustadora. Segundo Porter (1999), nesses casos, os gestores enfrentam um alto nível de incerteza sobre as necessidades dos clientes, sobre os produtos e serviços mais desejáveis e sobre a melhor configuração das atividades e tecnologias.

Nessas organizações, frequentemente, existe um histórico de tentativas frustradas, investimentos sem um retorno mensurável e até mesmo uma incredulidade da equipe operacional e da direção, em relação à eficácia dessas tecnologias. Esses fatos contribuem, ainda mais, para o aumento desse nível de incerteza e pressões sobre os gestores. Todos esses aspectos, aliados à dificuldade de mão de obra, à falta de capital de giro e às linhas de crédito,

REMIPE- Revista de Micro e Pequenas Empresas e Empreendedorismo da Fatec Osasco 
capazes de atender às necessidades dessas organizações, quase que inviabilizam esse processo de mudança. No entanto, o simples fato de não se abrir às mudanças têm estagnado muitas organizações, quando não proporcionam a falência destas.

Esse estudo demonstra sua relevância, no sentido de permitir uma análise da adoção de tecnologias de gestão (ERP), hoje fundamentais para que as empresas possam se tornar mais competitivas no mercado e atender às exigências legais. Porém, o estudo avança, quando se compromete a analisar o ponto de vista dos empresários e colaboradores. A literatura sobre o assunto apresenta uma série de resultados positivos e benefícios a serem obtidos com a adoção de ERP, porém, as dificuldades a serem enfrentadas, principalmente considerando as micro e pequenas empresas brasileiras, podem ser mais estudadas. Outro aspecto observado, são os grandes investimentos governamentais na implementação de controles informatizados da arrecadação, como por exemplo: a Nota Fiscal Eletrônica (NFE),qual integrou a emissão das Notas Fiscais em todos os 27 estados da federação; a Nota Fiscal de Serviço Eletrônico, no Rio de Janeiro, comumente conhecida como Nota Carioca, que atualmente já está presente em mais 800 cidades a Nota Fiscal de Consumidor Eletrônica (NFC-E),a qual está em processo de implementação em diversos estados brasileiros e tem por cronograma a total implantação até dezembro de 2017; além de outros sistemas de gestão da arrecadação como SPED, E-SOCIAL etc. Essas exigências governamentais, de certo modo, proporcionam aos empresários uma obrigatoriedade ao uso dos sistemas integrados de gestão (ERP), mas que por sua vez, precisam ser implementados a fim de realmente contribuir para o ganho competitivo das empresas e não apenas atender tais exigências.

\section{REFERENCIAL TEÓRICO:}

\subsection{MICRO E PEQUENAS EMPRESAS;}

A definição das Micro e Pequenas Empresas brasileiras (MPE) pode ser feita de duas formas alternativas. Segundo o SEBRAE (2006), pelo número de pessoas ocupadas na empresa ou pela receita auferida.

Critério 1 - Por número de pessoas ocupadas na empresa. Neste caso, considera-se microempresas, aquelas nas atividades de serviços e comércio com até 9 pessoas ocupadas; e como pequena empresa as que tenham entre 10 e 49 pessoas ocupadas. Na atividade industrial, 
são microempresas, aquelas com até 19 pessoas ocupadas; e pequenas empresas entre 20 e 99 pessoas ocupadas.

Critério 2 - Por nível de faturamento da empresa. Segundo a Lei Complementar No 123 , de 14 de dezembro de 2006, que instituiu o Estatuto Nacional da Microempresa e da Empresa de Pequeno Porte, considera-se microempresa, aquelas que aufiram em cada ano-calendário a receita bruta igual ou inferior a $\mathrm{R} \$ 360.000,00$ (trezentos e sessenta mil reais) ao ano; e no caso de empresa de pequeno porte, aquelas que aufiram em cada ano-calendário a receita bruta superior a $\mathrm{R} \$ 360.000,00$ (trezentos e sessenta mil reais) e, igual ou inferior a $\mathrm{R} \$ 4.800 .000,00$ (quatro milhões e oitocentos mil reais) ao ano.

Em 2011, o IBGE calculou em 27\% a participação dos pequenos negócios no PIB. Ou seja, mais de um quarto do Produto Interior Bruto brasileiro é gerado pelos micro e pequenos negócios. Isso demonstra claramente a importância das micro e pequenas empresas na economia brasileira e o quanto as mesmas precisam de investimentos e apoio para superar as desigualdades estruturais com os grandes concorrentes e os de economia global.

Segundo um estudo do SEBRAE (2014), no ano de 2011, a representatividade das MPE's por número de empresas, apresentou uma representatividade de 99,2\% no setor de comércio, 98,2\% no setor de serviços e 95,5\% no setor de indústrias. Esses percentuais justificaram os esforços no sentido de incentivar e melhor qualificar as micro e pequenas empresas, a fim de alavancar a economia nacional.

\subsection{SISTEMAS INTEGRADOS DE GESTÃO (ERP);}

Para definir um sistema integrado de gestão faz-se necessário entender o conceito do SIG - Sistema de Informações Gerenciais. De acordo com Batista (2013) e Chopra e Meindl (2016), os sistemas de informações gerenciais trabalham no auxílio da gestão, planejamento e controle de produção. São ferramentas capazes de gerir informações e relacionamentos entre setores, clientes, recursos humanos e fornecedores. Os "Sistemas de Informações Gerenciais" ou também conhecidos como "Sistemas Integrados de Gestão Empresarial" - SIG ou em inglês "Enterprise Resource Planning - ERP” são a evolução de outra metodologia conhecida como MRP e MRP II (Manufacturing Requeriment Planning). O MRP trata do registro de produção, como quantidade de material utilizado, tempo para produção e quantidade produzida para se projetar uma previsão de recursos a serem destinados à produção, quando se investir os recursos 
e o quanto será produzido. O MRP II, por sua vez, passou a atender às necessidades de informação para a tomada de decisão gerencial sobre todos os recursos de manufatura. $\mathrm{Na}$ sequência, novos módulos foram agregados ao MRP II, como por exemplo, Gerenciamento dos Recursos Humanos, Vendas e Distribuição, Finanças e Controladoria, ultrapassando os limites da manufatura, percorrendo toda a empresa e chegando ao seu estágio atual de desenvolvimento, caracterizando-se como um Sistema Integrado de Gestão - ERP (CHOPRA e MEINDL, 2016).

Um sistema integrado de gestão ERP se propõe a dar suporte a todos os processos e áreas funcionais de uma empresa a partir de uma base de dados única, na qual todas as transações estejam interligadas. Ele é composto por módulos integrados que atendem a cada área funcional ou processo, como Finanças, Produção, Custos, Vendas, RH etc.

O objetivo maior de um sistema de gestão ERP é a integração dos dados organizacionais e a sua disponibilização em tempo real. Com isso, ele promete interligar setores, unidades e filiais em diferentes locais, possibilitando a adoção de um único padrão de indicadores para a organização. Davenport (2000) define os sistemas ERP como pacotes de aplicações computacionais que dão suporte a maior parte das necessidades de informação das organizações.

Souza e Zwicher (2000) afirmam que os sistemas ERP são pacotes comerciais de softwares que incorporam modelos padrões de processos de negócios (as chamadas "bestpractices") e requerem procedimentos de ajuste para que possam ser utilizados em uma determinada empresa. Também permitem certa adequação das funcionalidades existentes por meio da parametrização. Este processo consiste na definição de diversos valores que são introduzidos no sistema, com o intuito de dimensionar o perfil da empresa e o comportamento do sistema. A orientação a processos é destacada por muitos autores na caracterização de ERP. Segundo Souza \& Zwicker (2000), os processos de negócio podem ser definidos como um conjunto de tarefas e procedimentos interdependentes, realizados para alcançar determinado resultado empresarial, sendo uma de suas características a transposição de fronteiras organizacionais. 


\subsection{A ADOÇÃO TECNOLÓGICA É UM PROCESSO MULTIDIMENSIONAL.}

A adoção de tecnologia, segundo Rogers (2003), é uma etapa crucial para todo o processo de desenvolvimento da inovação. É quando ela passa a ser adquirida e absorvida pelos adotantes. Quando ela começa a ser adotada por diversos outros adotantes, entende-se que está sendo difundida, transformando as descobertas científicas em prática.

Ampliando o modelo de adoção, Cribb et Al. (2011), a adoção tecnológica efetiva é um processo que envolve seleção, aquisição, implementação e absorção da tecnologia. Portanto, para explorar esse conceito deve-se considerá-lo como a um processo, que só se efetiva após o cumprimento de suas etapas.

Figura 1 - O Processo de Adoção Tecnológica:

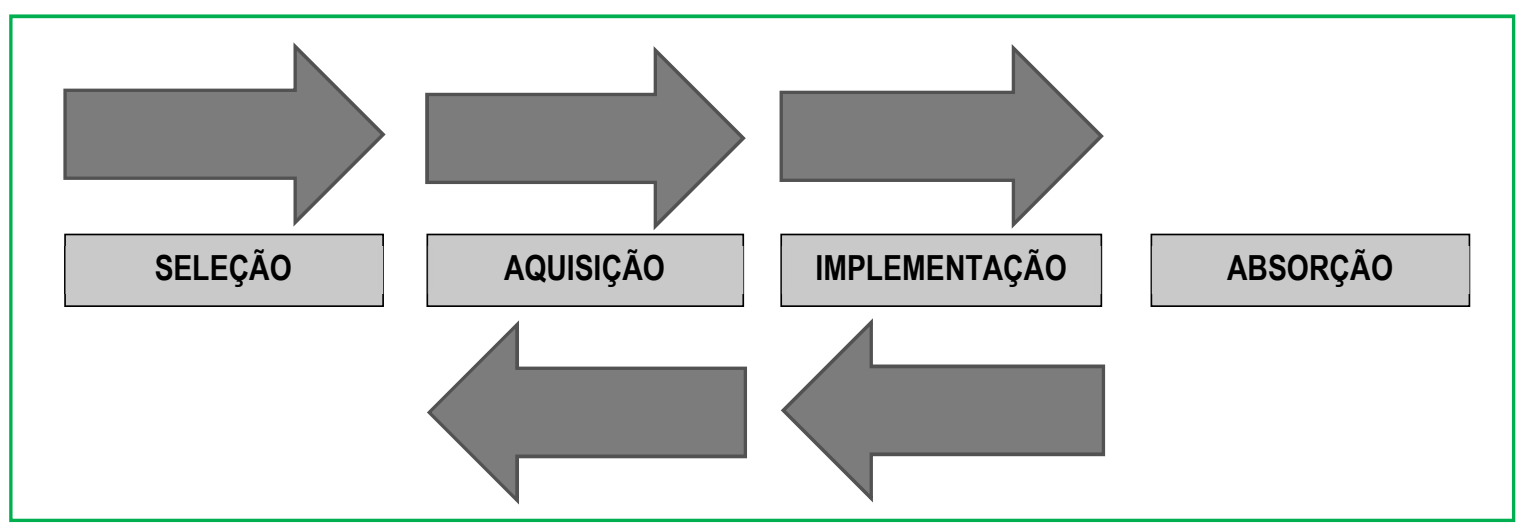

Fonte: Elaborada com base em CRIBB et al. (2011).

No estudo publicado por Cribb et al. (2011) sobre a adoção tecnológica na agricultura familiar dentro de uma perspectiva cooperativista, a adoção está descrita como um processo com quatro etapas:

A seleção da tecnologia deve ter como alicerce de sua escolha as características da mesma, bem como o seu desempenho. Mas também deve ser considerado o investimento necessário em relação ao benefício proposto e à capacidade financeira da empresa, perspectivas de mercado e metas de médio e longo prazo.

A aquisição da tecnologia pode ocorrer de fonte interna ou externa. Essas tecnologias podem ser adquiridas internamente por meio de departamentos de TI (Tecnologia da Informação), ou considerando a tendência mundial de terceirização dos serviços de TI, essa aquisição pode aproveitar as capacidades das empresas de TI do mercado, assim como,a experiência de concorrentes, fornecedores e seus departamentos de $\mathrm{P} \& \mathrm{D}$, ou até mesmo por

REMIPE- Revista de Micro e Pequenas Empresas e Empreendedorismo da Fatec Osasco 
intermédio de acordo contratuais, tais como licenças, acordos de $\mathrm{P} \& \mathrm{D}$ e joint ventures etc. (PISANO, 1990).

A implantação da tecnologia selecionada e adquirida é fundamental no processo de adoção tecnológica. Ela supõe a instalação dos componentes físicos, o treinamento do pessoal e a incorporação da tecnologia nas rotinas diárias da unidade produtiva (ROGERS, 2003). Também requer pesquisas e esforços adicionais, além de envolver vários parceiros e exigir coordenação e compromisso destes (HAUSMAN; STOCK, 2003).

A absorção da tecnologia refere-se à valorização, assimilação e aplicação da tecnologia para fins produtivos. A capacidade de absorção tecnológica pode ser criada como um subproduto dos investimentos em P\&D ou das próprias operações produtivas (COHEN; LEVINTHAL, 1990). Ela influencia positivamente a aquisição de tecnologias internamente ou externamente geradas (HARO DOMÍNGUEZ et al., 2007).

\section{METODOLOGIA:}

Foi realizada uma pesquisa com características de uma pesquisa de marketing, pois conforme Malhotra (2012), este tipo de pesquisa atua de forma sistêmica em um conjunto de informações, as quais são usadas para gerar ganhos no processo decisório, no tocante ao problema proposto e sua possível solução. Esse estudo realizou uma pesquisa descritiva (GIL, 2008), que permite a descrição das características de determinada população ou fenômeno, determinando opiniões sobre práticas ou opiniões atuais de uma população específica, bem como o estabelecimento de relações entre variáveis de uma pesquisa. Envolve ainda o uso de técnicas padronizadas de coleta de dados, tais como: questionário e observação.

Considerando uma abordagem quantitativa, a população-alvo do estudo foram as micro e pequenas empresas brasileiras, divididas nas 27 unidades federativas do Brasil, e contatadas mediante questionário eletrônico. Considerando o nível de confiança de $95 \%(Z=1,96)$ e aceitando uma margem de erro de $5 \%(\mathrm{E}=0,05)$, utilizando a expressão $\left[\mathrm{n}=\left(\mathrm{Z}^{2} * 1 / 4\right) / \mathrm{E}^{2}\right]$, segundo Barbetta (2010), logo $\left[\mathrm{n}=(1,96 * 1 / 4) / 0,05^{2}\right]$, resulta 396 (trezentos e noventa e seis), que pode-se considerar como o número mínimo de empresas o tamanho mínimo da amostra, capaz de garantir tal precisão, como geralmente acontece em pesquisas de levantamento (survey).A amostra vislumbrou empresas de cada unidade federativa do país, a fim de obter dados representativos de todos os estados brasileiros. Foram considerados estabelecimentos de diversos setores da economia, classificados como indústrias, comércios e prestadoras de

REMIPE- Revista de Micro e Pequenas Empresas e Empreendedorismo da Fatec Osasco 
serviço. Dentro das empresas selecionadas, identifica-se como sujeito da pesquisa, os proprietários, os gerentes, administradores, contadores ou responsáveis das áreas específicas, ligadas à gestão ou adoção da nova tecnologia. Desse modo, foram aplicados 419 (quatrocentos e dezenove questionários) no período de 01/07/2016 a 10/02/2017, sendo descartados 8 (oito) questionários da análise dos dados, uma vez que os mesmos correspondiam a empresas com um faturamento superior a $\mathrm{R} \$ 3.600 .000,00$ (três milhões e seiscentos mil reais), o que descaracterizou essas empresas como micro e pequenas empresas. A confiabilidade da pesquisa foi obtida por meio do controle na elaboração do protocolo de pesquisa e na coleta dos dados, permitindo assim a possiblidade de realizar a coleta em diferentes momentos. Também foram armazenados, em uma planilha, todos os resultados obtidos. Na execução do questionário (survey) considerou-se questões dicotômicas, escalas lineares, questões estruturadas e não estruturadas, oferecendo assim uma melhor compreensão da percepção do entrevistado em relação ao problema de pesquisa. O questionário foi aplicado obedecendo os seguintes critérios: (1)Internet: utilizando a ferramenta Google Forms ${ }^{\circledR}$, escolhida por sua praticidade de acesso à pesquisa. $\mathrm{O}$ entrevistado recebeu, por e-mail, um link que o direcionava para um formulário eletrônico e com isso não precisava de nenhum software instalado; (2) Ligações Telefônicas: pela qual o entrevistado recebia uma ligação do entrevistador. O entrevistador se apresentava e fazia as perguntas descritas no questionário. Nesse momento, o mesmo preenchia o formulário de pesquisa, considerando as respostas do entrevistado, utilizando-se da ferramenta Google Forms ${ }^{\circledR}$. Os entrevistados foram selecionados por intermédio de busca aleatória pela internet. Para garantir uma representatividade mínima de cada Unidade da Federação no estudo e assim reduzir a possibilidade de gerar um viés em relação aos estados e as regiões geográficas do país, foi considerada a relatividade das empresas existentes por estado, conforme dados do IBGE (2014), e mediante essa relatividade foi rateado proporcionalmente a quantidade de questionários previstos a serem realizados. Após a coleta de dados, os mesmos foram tabulados de forma a transformá-los em informações, segundo os entrevistados. Os dados foram processados e cruzados de acordo com as variáveis e cálculos estatísticos, proporcionando assim a realização dos testes de hipóteses. Para tanto, foram utilizadas planilhas eletrônicas (Excel ${ }^{\circledR}$, software integrante do pacote Microsoft Office) e o software de análise estatística (IBM SPSS Statistic Versão 22®).Quanto às medições dos atributos em importância (atributos elencados de forma ordinal),foram utilizadas análises de tendência central descritiva (médias, mediana e moda) e desvio (desvio padrão) conforme sugere Malhotra (2012), além do uso de tabelas cruzadas de dados e medidas de frequência.

REMIPE- Revista de Micro e Pequenas Empresas e Empreendedorismo da Fatec Osasco 


\section{RESULTADOS:}

Classificando as empresas pelo faturamento em 2015 (critério escolhido pelo estudo para classificação de porte das micro e pequenas empresas brasileiras), Tabela 1, pode-se inferir que a amostra se apresenta dividida em microempresas, com representatividade de 58,6\% e pequenas empresas 41,4\%. Também é possível observar, na Tabela 1, a participação das mesmas em relação ao seu estado.

Tabela 1 - Micro e Pequenas empresas segmentadas por Estado:]

\begin{tabular}{|c|c|c|c|c|c|}
\hline Estado & Microempresa & Delta (\%) & Pequena Empresa & Delta (\%) & Total \\
\hline Acre & 1 & $50,00 \%$ & 1 & $50,00 \%$ & 2 \\
\hline Alagoas & 1 & $33,30 \%$ & 2 & $66,70 \%$ & 3 \\
\hline Amapá & 0 & $0,00 \%$ & 2 & $100,00 \%$ & 2 \\
\hline Amazonas & 1 & $50,00 \%$ & 1 & $50,00 \%$ & 2 \\
\hline Bahia & 6 & $33,30 \%$ & 12 & $66,70 \%$ & 18 \\
\hline Ceará & 11 & $100,00 \%$ & 0 & $0,00 \%$ & 11 \\
\hline Distrito Federal & 3 & $42,90 \%$ & 4 & $57,10 \%$ & 7 \\
\hline Espírito Santo & 5 & $62,50 \%$ & 3 & $37,50 \%$ & 8 \\
\hline Goiás & 10 & $76,90 \%$ & 3 & $23,10 \%$ & 13 \\
\hline Maranhão & 3 & $60,00 \%$ & 2 & $40,00 \%$ & 5 \\
\hline Mato Grosso & 7 & $100,00 \%$ & 0 & $0,00 \%$ & 7 \\
\hline Mato Grosso do Sul & 2 & $33,30 \%$ & 4 & $66,70 \%$ & 6 \\
\hline Minas Gerais & 31 & $72,10 \%$ & 12 & $27,90 \%$ & 43 \\
\hline Pará & 6 & $100,00 \%$ & 0 & $0,00 \%$ & 6 \\
\hline Paraíba & 1 & $25,00 \%$ & 3 & $75,00 \%$ & 4 \\
\hline Paraná & 26 & $81,30 \%$ & 6 & $18,80 \%$ & 32 \\
\hline Pernambuco & 0 & $0,00 \%$ & 10 & $100,00 \%$ & 10 \\
\hline Piauí & 0 & $0,00 \%$ & 3 & $100,00 \%$ & 3 \\
\hline Rio de Janeiro & 20 & $64,50 \%$ & 11 & $35,50 \%$ & 31 \\
\hline Rio Grande do Norte & 1 & $25,00 \%$ & 3 & $75,00 \%$ & 4 \\
\hline Rio Grande do Sul & 14 & $41,20 \%$ & 20 & $58,80 \%$ & 34 \\
\hline Rondônia & 5 & $71,40 \%$ & 2 & $28,60 \%$ & 7 \\
\hline Roraima & 0 & $0,00 \%$ & 1 & $100,00 \%$ & 1 \\
\hline Santa Catarina & 11 & $50,00 \%$ & 11 & $50,00 \%$ & 22 \\
\hline São Paulo & 74 & $58,70 \%$ & 52 & $41,30 \%$ & 126 \\
\hline Sergipe & 0 & $0,00 \%$ & 2 & $100,00 \%$ & 2 \\
\hline Tocantins & 2 & $100,00 \%$ & 0 & $0,00 \%$ & 2 \\
\hline Total & 241 & $58,60 \%$ & 170 & $41,40 \%$ & 411 \\
\hline
\end{tabular}

Fonte: Elaborada pelo autor a partir dos dados do IBGE (2014) e dados da pesquisa.

Em relação à Adoção de Tecnologia, a pesquisa demonstrou um alto índice de desconhecimento dos entrevistados das micro e pequenas empresas em relação ao termo "Adoção de Tecnologia", assim como, sobre a metodologia que está atrás do termo proposto. Por meio da Tabela 2 é possível verificar que $61,8 \%$ dos entrevistados não conheciam o termo 
"Adoção de Tecnologia". Esse número se agrava, quando se focaliza nas microempresas, que $66 \%$ dos entrevistados afirmaram não conhecer o termo "Adoção de Tecnologia".

Tabela 2 - Nível de conhecimento dos entrevistados sobre Adoção de Tecnologia:

\begin{tabular}{l|r|r|r|r|r}
\hline & Frequência & Delta (\%) & Frequência & Delta (\%) & Frequência \\
\hline & \multicolumn{2}{|c|}{ Não } & \multicolumn{2}{|c|}{ Sim } & Total \\
\hline MICROEMPRESA & 159 & $66,00 \%$ & 82 & $34,00 \%$ & 241 \\
\hline PEQUENA & 95 & $55,90 \%$ & 75 & $44,10 \%$ & 170 \\
EMPRESA & 254 & $61,80 \%$ & 157 & $38,20 \%$ & 411 \\
\hline TOTAL & & & &
\end{tabular}

Fonte: Elaborado pelo autor.

Tabela 1 - Estatística t uma amostra - Conhece o termo Adoção de Tecnologia?

\begin{tabular}{l|r|r|r|r|r|r|r|r}
\hline & $\mathrm{N}$ & Média & $\begin{array}{c}\text { Desvio } \\
\text { Padrão }\end{array}$ & $\begin{array}{r}\text { Erro padrão } \\
\text { da média }\end{array}$ & $\mathrm{t}$ & \multicolumn{1}{c}{ Df } & $\begin{array}{c}\text { Sig. (2 } \\
\text { extremidades) }\end{array}$ & $\begin{array}{c}\text { Diferença } \\
\text { média }\end{array}$ \\
\hline $\begin{array}{l}\text { Conhece o termo Adoção de } \\
\text { Tecnologia? }\end{array}$ & 411 & 0,38 & 0,486 & 0,024 & $-4,918$ & 410 & 0,000001 & $-0,118$ \\
\hline
\end{tabular}

Fonte: Elaborado pelo autor.

Com base no teste da hipótese Ha (A maioria dos gestores das micro e pequenas empresas brasileiras conhece o termo "Adoção de Tecnologia"), rejeita-se H0, uma vez que foi aplicado o teste t-Stutent de uma amostra, do total de entrevistados. O teste t-Stutentconsiderou um grau de confiança de $95 \%$ e 5\% de significância.

Observando as micro e pequenas empresas e a adoção de um sistema integrado de gestão (ERP), percebe-se que a quantidade de empresas que adotou um sistema integrado de gestão (ERP) representa um pouco mais da metade das empresas $(51,1 \%)$. Isso demonstra o potencial de micro e pequenas empresas que ainda pode ser explorado na adoção dessas tecnologias e como a adoção de tais sistemas pode contribuir para o crescimento das mesmas. No entanto, observando a relação entre as micro e pequenas empresas, verificou-se que apenas $35,3 \%$ das microempresas possuem um sistema integrado de gestão ERP, contra $73,5 \%$ das pequenas empresas que possuem um sistema integrado de gestão. Com base no teste da hipótese $\mathrm{Hb}$ (a maioria das micro e pequenas empresas brasileiras possui um sistema integrado de gestão), aceita-se H0, uma vez que foi aplicado o teste t-Stutent de uma amostra, do total de empresas. O teste t-Stutent considerou um grau de confiança de 95\% e 5\% de significância.

Tabela 2 - Estatística t uma amostra - Possui ERP? 


\begin{tabular}{l|r|r|r|r|r|r|r|r}
\hline & \multicolumn{1}{c|}{$\mathrm{N}$} & Média & $\begin{array}{c}\text { Desvio } \\
\text { Padrão }\end{array}$ & $\begin{array}{c}\text { Erro padrão } \\
\text { da média }\end{array}$ & \multicolumn{1}{c|}{$\mathrm{T}$} & $\mathrm{df}$ & Sig. (unicaudal) & $\begin{array}{c}\text { Diferença } \\
\text { média }\end{array}$ \\
\hline Possui ERP? & 411 & 0,51 & 0,5 & 0,025 & 0,444 & 410 & 0,329 & 0,011 \\
\hline
\end{tabular}

Fonte: Elaborado pelo autor.

Mediante as informações coletadas e observando os entrevistados que possuem um sistema integrado de gestão (ERP), foram medidos os principais módulos que compõem um sistema integrado de gestão ERP e o grau de adoção de cada um. Considerou-se a aplicação do mesmo ao negócio, se está em processo de implementação ou se se está implementado. De acordo com a Tabela 5, os módulos mais implementados nas microempresas, em ordem de adoção, são: Financeiro (88,2\%), Clientes $(87,1 \%)$, Orçamentos $(83,5 \%)$ e Estoque $(80 \%)$. E nas pequenas empresas são: Orçamentos $(77,6 \%)$, Financeiro $(75,2 \%)$ e Ponto de Venda (70,4\%). Quando observada a inaplicabilidade dos módulos, observou-se nas microempresas que os módulos com maior inaplicabilidade são: Distribuição (31,8\%) e Produção (30,6\%). E nas pequenas empresas são: Clientes e Recursos Humanos (ambos com 29,6\%). 
Tabela 5 - Módulos adotados pelas micro e pequenas empresas:

\begin{tabular}{|c|c|c|c|c|c|c|c|}
\hline & \multicolumn{2}{|c|}{ Microempresa } & \multicolumn{2}{|c|}{ Pequena Empresa } & \multicolumn{2}{|c|}{ Total } \\
\hline & & Contagem & Relativo (\%) & Contagem & Relativo (\%) & Contagem & $\begin{array}{c}\text { Relativo } \\
(\%)\end{array}$ \\
\hline \multirow{3}{*}{ Orçamentos } & Não se aplica & 12 & $14,10 \%$ & 13 & $10,40 \%$ & 25 & $11,90 \%$ \\
\hline & Em Implantação & 2 & $2,40 \%$ & 15 & $12,00 \%$ & 17 & $8,10 \%$ \\
\hline & Implementado & 71 & $83,50 \%$ & 97 & $77,60 \%$ & 168 & $80,00 \%$ \\
\hline \multirow{3}{*}{ Ponto de Venda } & Não se aplica & 20 & $23,50 \%$ & 25 & $20,00 \%$ & 45 & $21,40 \%$ \\
\hline & Em Implantação & 10 & $11,80 \%$ & 12 & $9,60 \%$ & 22 & $10,50 \%$ \\
\hline & Implementado & 55 & $64,70 \%$ & 88 & $70,40 \%$ & 143 & $68,10 \%$ \\
\hline \multirow{3}{*}{ Distribuição } & Não se aplica & 27 & $31,80 \%$ & 30 & $24,00 \%$ & 57 & $27,10 \%$ \\
\hline & Em Implantação & 9 & $10,60 \%$ & 13 & $10,40 \%$ & 22 & $10,50 \%$ \\
\hline & Implementado & 49 & $57,60 \%$ & 82 & $65,60 \%$ & 131 & $62,40 \%$ \\
\hline \multirow{3}{*}{ Clientes } & Não se aplica & 11 & $12,90 \%$ & 37 & $29,60 \%$ & 48 & $22,90 \%$ \\
\hline & Em Implantação & 0 & $0,00 \%$ & 11 & $8,80 \%$ & 11 & $5,20 \%$ \\
\hline & Implementado & 74 & $87,10 \%$ & $\overline{77}$ & $61,60 \%$ & 151 & $71,90 \%$ \\
\hline \multirow{3}{*}{ Recursos Humanos } & Não se aplica & 22 & $25,90 \%$ & 37 & $29,60 \%$ & 59 & $28,10 \%$ \\
\hline & Em Implantação & 12 & $14,10 \%$ & 12 & $9,60 \%$ & 24 & $11,40 \%$ \\
\hline & Implementado & 51 & $60,00 \%$ & 76 & $60,80 \%$ & 127 & $60,50 \%$ \\
\hline \multirow{3}{*}{ Estoque } & Não se aplica & 11 & $12,90 \%$ & 35 & $28,00 \%$ & 46 & $21,90 \%$ \\
\hline & Em Implantação & 6 & $7,10 \%$ & 3 & $2,40 \%$ & 9 & $4,30 \%$ \\
\hline & Implementado & 68 & $80,00 \%$ & 87 & $69,60 \%$ & 155 & $73,80 \%$ \\
\hline \multirow{3}{*}{ Produção } & Não se aplica & 26 & $30,60 \%$ & 24 & $19,20 \%$ & 50 & $23,80 \%$ \\
\hline & Em Implantação & 5 & $5,90 \%$ & 16 & $12,80 \%$ & 21 & $10,00 \%$ \\
\hline & Implementado & 54 & $63,50 \%$ & 85 & $68,00 \%$ & 139 & $66,20 \%$ \\
\hline \multirow{3}{*}{ Financeiro } & Não se aplica & 9 & $10,60 \%$ & 18 & $14,40 \%$ & 27 & $12,90 \%$ \\
\hline & Em Implantação & 1 & $1,20 \%$ & 13 & $10,40 \%$ & 14 & $6,70 \%$ \\
\hline & Implementado & 75 & $88,20 \%$ & 94 & $75,20 \%$ & 169 & $80,50 \%$ \\
\hline \multicolumn{2}{|l|}{ Total } & 85 & $100,00 \%$ & 125 & $100,00 \%$ & 210 & $100,00 \%$ \\
\hline
\end{tabular}

Fonte: Elaborado pelo autor.

Considerando o Nível de Satisfação das empresas adotantes de sistemas integrados de gestão (ERP), é possível perceber, segundo os resultados obtidos, que a maioria das empresas está "Satisfeita" (67,1\%) ou "Totalmente Satisfeita" (26,2\%) com a adoção do sistema integrado de gestão ERP. Esse grau de satisfação se repete, na mesma tendência, tanto para as microempresas quanto para as pequenas empresas, como se pode visualizar na Tabela 6 . No entanto, se focalizar no total de adotantes "totalmente satisfeitos", observa-se que apenas $26,2 \%$ dos mesmos foram plenamente atendidos pela adoção do sistema integrado de gestão, o que abre perspectivas para a melhoria do processo de adoção desde a seleção até a absorção da tecnologia.

REMIPE- Revista de Micro e Pequenas Empresas e Empreendedorismo da Fatec Osasco 
Tabela 6 - Nível de satisfação em relação a adoção de um sistema ERP:

\begin{tabular}{l|r|r|r|r|r|}
\hline & \multicolumn{4}{|c|}{ Nível de Satisfação para Adoção } & Total \\
\cline { 2 - 6 } & $\begin{array}{r}\text { Totalmente } \\
\text { insatisfeito }\end{array}$ & Insatisfeito & Satisfeito & $\begin{array}{r}\text { Totalmente } \\
\text { satisfeito }\end{array}$ & \\
\hline Microempresa & 6 & 0 & 52 & 27 & 85 \\
\hline$\%$ & $7,10 \%$ & $0,00 \%$ & $61,20 \%$ & $31,80 \%$ & $100 \%$ \\
\hline Pequena Empresa & 8 & 0 & 89 & 28 & 125 \\
\hline$\%$ & $6,40 \%$ & $0,00 \%$ & $71,20 \%$ & $22,40 \%$ & $100 \%$ \\
\hline Total & 14 & 0 & 141 & 55 & 210 \\
\hline$\%$ & $6,70 \%$ & $0,00 \%$ & $67,10 \%$ & $26,20 \%$ & $100 \%$ \\
\hline
\end{tabular}

Fonte: Elaborado pelo autor.

Tabela 7 - Teste-t Student e Teste Levene (Nível de Satisfação):

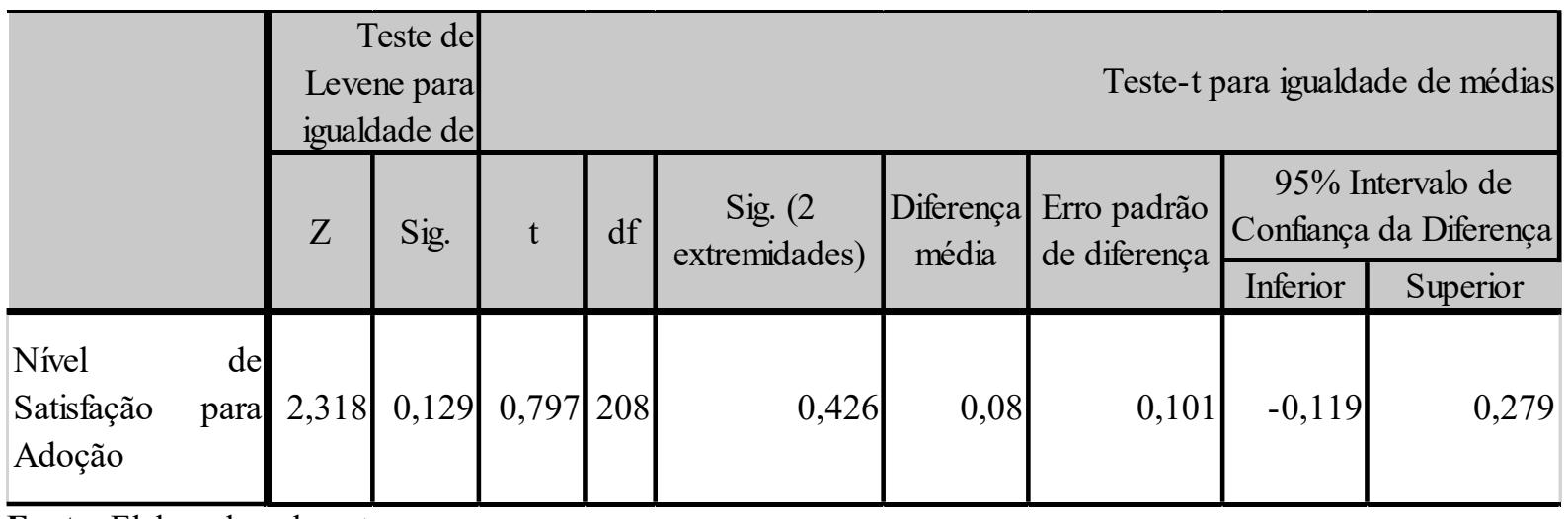

Fonte: Elaborado pelo autor.

Com base no teste da hipótese $\mathrm{Hd}$ (os gestores das micro e pequenas empresas brasileiras estão satisfeitos com a adoção do sistema integrado de gestão ERP), aceita-se H0, uma vez que foi aplicado o teste t-Stutent de amostras independentes, do total de entrevistados, o tipo de empresa (micro e pequenas empresas) e o nível de satisfação em relação à adoção do sistema integrado de gestão ERP. Também foi aplicado o teste Levene para confirmar a igualdade de variância entre as duas amostras, o que foi confirmado mediante o grau de significância. O teste t-Stutent de amostra independente e o teste Leveneconsideram um grau de confiança de 95\% e $5 \%$ de significância.

\section{CONSIDERAÇÕES FINAIS:}


O diagnóstico da situação de adoção dos sistemas integrados de gestão (ERP) nas micro e pequenas empresas brasileiras pesquisadas, possibilitou algumas considerações:

Em relação à Adoção de Tecnologia, a pesquisa demonstrou um alto índice de desconhecimento dos entrevistados das micro e pequenas empresas em relação ao termo “Adoção de Tecnologia”, e, consequentemente, a metodologia que está atrás do termo proposto. Esse fato oportuniza ao governo a possibilidade de fomentar a criação de programas de política pública, em parceria com instituições de ensino, para capacitação e disseminação do conhecimento em relação à Adoção de Tecnologias para as micro e pequenas empresas.

Foi possível identificar que apenas $51,1 \%$ das empresas estudadas possuem um sistema integrado de gestão (ERP), gerando assim uma grande oportunidade de avanço tecnológico, eficiência e melhorias dos processos para quase a metade das micro e pequenas empresas brasileiras. Foi constatado que esse número se agrava muito mais, quando se observa o universo das microempresas, no qual apenas 35,3\% delas possuem um sistema integrado de gestão (ERP). Nesse contexto, incentivos para a adoção desses sistemas pode ser considerado como uma medida a ser aplicada.

Quanto aos módulos adotados pelas micro e pequenas empresas, observou-se a prioridade para os módulos Financeiro, Orçamentos, Estoque e Clientes, em relação aos outros módulos como Relacionamento com Clientes, Vendas, Caixa e Tesouraria.

\section{REFERÊNCIAS:}

ADDO, R.; Article: Enterprise Resource Planning (ERP): A Review Literature Report. The World Congress on Engineering and Computer Science 2011 Vol II WCECS 2011, October 19-21, 2011, San Francisco, USA.

ALRECK, P.; SETTLE, R. B. The survey research handbook. 3nd. ed. Chicago: Irwin, 2004.

BALLOU, Ronald H. Gerenciamento da cadeia de suprimentos / logística empresarial. $5^{\mathrm{a}}$ ed. Porto Alegre: Bookman, 2006.

BATISTA, Emerson O. Sistemas de Informação: o uso consciente da tecnologia para o gerenciamento. $2^{\mathrm{a}}$ ed. São Paulo. Editora Saraiva, 2013.

BARBETTA, Pedro Alberto; Estatística Aplicada às Ciências Sociais. Editora UFSC.

$7^{\mathrm{a}}$ ed. revisada, Florianópolis, 2010. 
BNDES, Circular 11/2010 para definição do Porte das empresas. Site IBGE. Disponível em: http://www.bndes.gov.br/SiteBNDES/bndes/bndes_pt/Institucional/Apoio_Financeiro/porte.ht

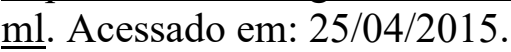

BOSTROM, R. AND HEINEM, J. MIS Problems and failures: a socio-technical perspective Part I: the causes. MIS Quarterly, September, 17 - 32. 1997.

BUONANNO, G., FAVERIO, P., et al. Factors affecting ERP system adoption: a comparative analysis between SMEs and large companies. Journal of Enterprise Information Management, Vol. 18, No. 4. 2005.

BRUNI, ADRIANO LEAL, SPSS: Guia prático para pesquisadores - São Paulo: Atlas, 2012.

CERTO, Samuel C., Administração Estratégica: planejamento e implantação de estratégias. $3^{\text {a }}$ ed. São Paulo: Pearson, 2010.

CHOPRA, S.; MEINDL. Gerenciamento da Cadeia de Suprimentos - Estratégia, Planejamento e Operação. $6^{\text {a }}$ ed. Prentice Hall, 2016.

COHEN, W. L.; LEVINTHAL, D. A. Absorptive capacity: a new perspective on learning and innovation. Administrative Science Quarterly, Ithaca, v. 35, n. 1, p. 128-152, 1990.

CORTES, Soraya M. Vargas. Como fazer análise qualitativa de dados. In: BÊRNI,

Duílio de Avila (Org.). Técnicas de pesquisa em economia: transformando curiosidade em conhecimento. Florianópolis: Ganges, 1998.

CRESWELL, John W. Projeto de pesquisa: métodos qualitativos, quantitativo e misto. $3^{\mathrm{a}}$ ed. Porto Alegre: Artmed, 2010.

CRIBB, A. Y. Determinantes da transferência de tecnologia na agroindústria brasileira de alimentos: identificação e caracterização. Journal of Technology Management and Innovation, Santiago, v. 4, p. 89-100, 2009.

CRIBB, A. Y.; CRIBB, S. L.; JUNIOR, M. F.; SILVA, F. T. Adoção Tecnológica e Gestão Cooperativista: Um estudo de caso na Agricultura Familiar. Cadernos de Ciência \& Tecnologia, Brasília, v. 28, n. 1, p. 133-157, jan./abr. 2011.

DAVENPORT, T. H. Mission critical: realizing the promise of enterprise systems. Boston, Massachusetts: Harvard Business School Press, 2000.

GIL, Antonio Carlos. Métodos e técnicas de pesquisa social. $6^{\mathrm{a}}$ ed. São Paulo: Atlas, 2008.

IBGE, Estatísticas do cadastro central de empresas: 2014, Coordenação de Metodologia das Estatísticas de Empresas, Cadastros e Classificações. - Rio de Janeiro: IBGE, 2016.

HARO DOMÍNGUEZ, M. C.; ARIAS ARANDA, D.; LLORÉNS-MONTES, F. J.; MORENO, A. R. The impact of absorptive capacity on technological acquisitions engineering consulting companies. Technovation, [Amsterdam], v. 27, n. 8, p. 417-425, 2007. 
HAUSMAN, A.; STOCK, J. R. Adoption and implementation of technological innovations within long-term relationships. Journal of Business Research, New York, v. 56, n. 8, p. 681686, 2003.

KOCH, C.; SLATER D.; BAATZ, E. The ABCs of ERP. Disponível na Internet em http://www.cio.com. Acessado em 22 de agosto de 2015.

LAUDON, Kenneth C.; LAUDON, Jane Price. Sistemas de informação gerenciais: administrando a empresa digital. São Paulo: Pearson Education do Brasil, 2014.

LIMA, A. D. A. et al. Implantação de pacote de gestão empresarial em médias empresas. Artigo publicado pela KMPress. Disponível em: http://www.kmpress.com.br. Disponível em: 13 fev. 2000. Acesso em: 27 out. 2015.

KERLINGER, Fred Nichols. Metodologia da Pesquisas em Ciências Sociais: um tratamento conceitual. São Paulo: EPU, EDUSP, 1979.

MALHOTRA, Naresh K. Pesquisa de marketing: uma orientação aplicada. 6 Ed., Bookman Editora, 2012.

MARCONI, Marina de Andrade; LAKATOS, Eva Maria. Fundamentos de Metodologia Científica. $8^{\text {a }}$ ed. São Paulo: Atlas, 2017.

MENDES, J. V.; ESCRIVÃO FILHO, E. O sistema integrado de gestão é fator de competitividade para as pequenas e médias empresas? Revista Uniara, n. 8, p. 13-21, 2000.

OLIVEIRA, M. A., RAMOS, A. S. M. Fatores de Sucesso na Implementação de Sistemas Integrados de Gestão Empresarial (ERP): Estudo de Caso em uma Média Empresa. In: Encontro Nacional de Engenharia de Produção. Anais. Curitiba, 2002.

PINTO, A. Ponto de Vista. Revista SA Perspectiva, São Paulo: nº 6-8, p.62-63., 1998.

PISANO, G. P. The R\&D boundaries of the firm: an empirical analysis. Administrative Science Quarterly, Ithaca, v. 35, n. 1, p. 153-176, 1990.

PORTER, M. E. Competição: estratégias competitivas essenciais. Rio de Janeiro: Ed. Campus, 1999.

RASHID, A. M.; HOSSAIN, L.; PATRICK, J. D. The Evolution of ERP Systems: A Historical Perspective. Idea Group Publishing. 2002.

ROGERS, E. M. Diffusion of innovations. 5th Edition. New York: Free Press, 2003.

SEBRAE, Participação das Micro e Pequenas Empresas na Economia Brasileira. SEBRAE, 2014.

SOBRAL, F. PECI, A. Administração. Teoria e prática no contexto brasileiro. São Paulo: Pearson Prentice Hall, 2008.

SOUZA, C. A.; ZWICKER, R. Implementação de Sistemas ERP: um estudo de casos comparados. Anais do $24^{\circ}$. Encontro da ANPAD. Florianópolis (SC), setembro de 2000.

REMIPE- Revista de Micro e Pequenas Empresas e Empreendedorismo da Fatec Osasco 
REMIPE

STEVENSON, William J. Estatística Aplicada à Administração. Editora Harbra. São Paulo, 2001. 